López I. y cols.

Rev. Chil. Pediatr. 65 (3); 154-157, 1994

\title{
Afecciones respiratorias bajas en el lactante: magnitud y factores de riesgo
}

\author{
Ilse M. López; Haydée Sepúlveda B. ${ }^{2}$; Isabel Valdés I. ${ }^{3}$
}

\section{Risk factors in infants with lower respiratory tract diseases}

\begin{abstract}
Lower respiratory tract diseoses, prospectively tracked along the first eighleen months of life, in $\mathbf{4 2 3}$ heolithy infonts born belween may 1,1991 and april 30,1992 and conlioled at an out pacienl clinic at northern melropolitan Santiago, Chile, are described. A tolal of $B 77$ lower respiralory episodes of illness were delected in the study period. Global incidence rates were $17.3 \%$ in the first six months, $10.3 \%$ in the second semester and $16.7 \%$ in to the third semester for each child month observation. The most common diagnosls was bronchilis $\mid 46.6 \%)$ followed by wheezy branchitis $\{40.1 \%$ and pneumania [13.2\% . The development of lower respirclory tracl illness showed prelesence for male gender of inforts, lower malernal educotion and robacco smaking habit of mothers or other farmily members. Children born from december throughout lebruary (southern hemisfere summer) showed higher incidence of bronchitis and wheezy bronchilis in their tirst six months of life than those born in olher months.
\end{abstract}

(Key words: infanis, lower respiratory lract infectiens.)

Las infecciones respiratorias en niños constituyen un problema serio de salud. Se ha recomendado realizar un esfuerzo mundial contra las afecciones respiratorias, para disminuir la mortalidad que causan en esta edad ${ }^{1}$. Si bien estas enfermedades se ubican con mayor frecuencia en las vías respiratorias altas, las que afectan a las vías bajas son más importantes, pues predisponen a enfermedades crónicas obstructivas posteriores, requicren tratamientos caros, son la primera causa de hospitalización en lactantes y la tercera causa de muerte ${ }^{2-4}$. Ellas son, en especial durante el primer año de vida, más frecuentes ante ciertos factores, como consumo de cigarrillo en el hogar -sobre todo por la madre-, cscasa escolaridad de ésta, nivel socioeconónico bajo, duración breve de la lactancia materna, scxo y época del año en que nace el niño $0^{5,8}$. En este estudio sc mide la frecuencia de las afccciones respiratorias bajas según diagnóstico en cada uno de los tres primeros semestres de vida y se analiza la influencia de algunos factores de riesgo para el lactante.

1. Escuela de Salud Pública.

2. Consultorio José Symon Ojeda. Municipalidad de Conchalí.

3. Unidad Enfermedades Respiratorias, Hospital Roberio dcl Rśo.

Proyecto Fondecyt 92-1091.

\section{Material y Método}

Se realizó un estudio prospectivo longitudinal de una cohorte de 423 niños sanos, nacidos entre el 1 de mayo de 1991 y el 30 de abril de 1992, con peso nomal, controlados desde los primeros días de vida hasla los 18 meses de cdad en cl Consultorio José Symon Ojeda del Servicio de Salud Metropolitano Norte. Se analizanon las bronquitis (ficbre, tos productiva, ausencia de síndrome obstruclivo y de signos clínicos o radiológicos de condensación pulmonar), síndrome bronquial obstructivo (sibilancias, roncus, espiración prolongada) y neumopatías (dificultad respiratoria, signos clinicos o radjológicos de condensación alveolar o de inflamación del inicrsticio pulmonar, incluyendo bronconeumonía y ncumonitis). Los diagnósticos fueron realizados por los médicos del consulırio, del servicio de urgencia del Iospital Roberto del Río o de la consulta privada. La información sobre las enfemedades detectadas fuera del consultorio se obtuvo interrogando sistemátjcamente a ls madre en cada control de salud del niño y por los regisiros que hizo clla misma en un cuademo proporcionado para estos fines. Ademăs, al incorporar al njĩo al estudio y luego a $\operatorname{los} 6,12$ y 18 meses, las madres fueron entrevistadas para registrar sus anteccdentes personales, de consumo de tabaco por ellas y olras personas del hogar, tipo de combustibles empleados en la calefacción de la casa y la infomación necesaria para calificar la situación socioeconórnica en una escala de Grafiar modificada?.

Se incluyeron 423 nin̄os en el análisis del primer sencstre, 395 en el regundo. Se excluyeron 28 niños que se trasladaron de consultorio durante este periodo; para el tercer trimestre se incorporaron sólo 305 casos, pues no todos habían cumplido 18 meses de edad al término de este infor- 
me. Entre los niños que prescntaron enfemedad, se calculb el promedio de episodios de afección respiratoria baja de cada uno de ellos, por semestre y para todo el período. Se analizó además la relación entre las enfermedades respiratorias bajas y algunas variables del niño, de ta madre y del ambiente. Para los análisis estadísticos se aplicó la prueba de significación para comperación entre proporciones.

\section{Resultados}

Al nacer, el peso promedio de los niños ( $\mathrm{n}$ : 229) era $3432 \mathrm{~g} \mathrm{y} 3291 \mathrm{~g}$ en las nifías (n: 194). La talla fuc $50,3 \mathrm{~cm}$ y $49,4 \mathrm{~cm}$ respectivamente. La duración promedio de la lactancia materna exclusiva fue de 4 meses en ambos sexos. Las madres tenían en promedio 25,5 años al nacer el niño, sólo $12 \%$ eran menores de 19 años; no más de $20 \%$ trabajaban fucra del hogar; su escolaridad promedio era 9.8 años y $14 \%$ había aprobado menos de 8 años de estudio. Veinticinco por ciento de las madres fumó durante el primer semestre de vida del niño y $31,1 \%$ durante el segundo semestre. En general más de $70 \%$ de los niños estuvieron sometidos a un ambiente con humo de tabaco desde su nacimiento, considerando tanto el hábito de la madre como de otros micmbros del grupo familiar.

De los 305 niños que completaron 18 meses de observación, $235(77 \%)$ sufricron al menos un episodio de enfermedad respiratoria baja. Las proporciones en que ocurrieron estas afecciones en los lactantes fueron diferentes en cada uno de los semestres analizados. Las de niños que padecieron bronquitis variaron de $42,1 \%$ ел el primer semestre a $32,6 \%$ en el segundo y a $21,0 \%$ en el tercero. Los porcentajes de síndrome bronquial obstructivo fueron $30,0 \%, 27,8 \%$ y $16,7 \%$, respectivamente, y los de neumonías $15,0 \%, 10,2 \%$ y $8,5 \%$ respeclivamente. El máximo de episodios de bronquitis por niño, cn cada semestre, fue cuatro, de síndrome bronquial obstructivo cinco y neumonia cuatro. El total de cpisodios de afecciones respiratorias bajas, en los 235 niños que completaron 18 meses de estudio, fue 877 : $13,2 \%$ neumonia, $40,1 \%$ síndrome bronquial obstructivo y $46,6 \%$ bronquitis.

El promedio de episodios de bronquitis -por paciente- en los tres semestres fue 1,3 y para los 18 meses 2,0. En el caso de síndrome bronquial obstructivo la cifra fue 1,5 en el primer semestre y 1,4 en los dos siguientes, siendo 2,3 en e] período total de observación. El promedio de neumonía -por paciente- fue $1,28,1,18$ y 1,0 en cada semestre y $1,59 \mathrm{cn}$ los 18 meses de observación. Considerando el total de episodios respiratorios bajos, el promedio era 2,15 en el primer semestre, 1,96 en el segundo y 1,90 en el tercero. Para quienes completaron el estudio, el promedio fue de 3,73 episodios en los 18 meses.

La gravedad de los episodios se puede expresar a través de las hospitalizaciones: hubo 21 casos $(4,9 \%$ ) en el primer semestre (20 varones) y 45 casos $(10,6 \%)$ a lo largo de todo el estudio (37 varones). Las causas de la hospitalización fucron neumopatías y síndrome bronquial obstructivo grave, pero sólo dos pacientes fallecieron a lo largo de los dieciocho meses del estudio, ambos en el primer trimestre, por neumopatía $y$, además, en su domicilio. Ciento treinta y seis $(44,6 \%)$ de los 305 niños estudiados hasta los 18 meses presentaron dos o las tres afecciones analizadas a lo largo de este período; $99(33,4 \%)$ sólo una y $70(23 \%)$ ninguna.

Las bronquitis afectaron en igual proporción a varones y mujeres; en cambio, los sindromes obstructivos y las neumonias fueron significativamente más frecuentes en los varones durante el primer scmesure de vida ( $\mathrm{p}<0,05)$. Los niños que vivían en ambientes de fumadores sufrieron bronquitis con mayor frecuencia en el primer semestre, sindrome bronquial obstructivo en el segundo y neumonías en el primer y tercer semestre.

La condición socioeconómica era muy homogénea, pues $81,6 \%$ de los participantes se ubicaba en el estrato medio bajo y bajo de Graffar, el resto $(18.4 \%)$ en el medio, lo que hace difícil establecer relaciones entre esa variable y las enfermedades analizadas, pero en el nivel más bajo las frecuencias de bronquitis y sindrome bronquial obstructivo fueron significativamente mayores. La escolaridad matema (uno de los componentes del indicador socioeconómico) menor que ocho años, se asoció con un riesgo significativamente mayor de cnfermedades respiratorias bajas en los niños.

El uso de paralina, leña o carbón para calefaccjonar representó mayor riesgo de bronquitis, sindrome bronquial obstructivo y neumonía en el segundo semestre de vida. Además, los nifos nacidos en los meses cálidos (diciembre, enero o febrero) mostraron tasas significativamente más altas de bronquitis y síndrome bronquial obstructivo en el primer semestre de vida. 


\section{Comentario}

Los resultados de este estudio justifican la proocupación de las organizaciones de salud por las enfermcdades respiratorias, pues al cabo de dicciocho meses de vida, tres de cada cuatro niños habian sufrido enfermedades respiratorias bajas, proporción que resulta muy alta si se la compara, por ejemplo, con menos de $30 \%$ en Tucson, Arizona $^{10,11}$, y correspondc a alrededor de 17 episodios por cada 100 niño-mes de observación para el período. Asimismo, más de la mitad de los episodios eran de cnfermedades graves (sindrome bronquial obstructivo y neumonía), que en cicrtas ocasiones pucden requerir hospitalizaciones y cuidados especiales e incluso causar mueries.

Las neumonias molivan la mayor preocupación, pues consiluyen la tercera causa de muerte en el primer año de vida y produjeron las únicas muertes ocurridas en el seguimiento que se. comenta. Por haber ocurrido ambas en los primeros mescs de vida y en el hogar, es razonable pensar que las acciones de salud en atención primaria deben ser dirigidas a mejorar globalmente las condiciones de salud infantil con especial énfasis en educación a la población sobre los riesgos de estas cnfermedades en la infancia.

La proporción de niños con afecciones respiratorias bajas disminuyó a medida que aumentaba la edad; sin embargo, el promedio de episodios no descendió significativamente, lo que indica que quienes presentan el riesgo lo mantienen, a lo menos durante un seguimiento de esta duración. La frecuencia de hospitalizaciones originó una tasa de $10,6 \%$, mucho más alta que la de $1 \%$ descrita en países más desarrollados ${ }^{11}$. Llama la atención la notablemente mayor proporción de hospitalizaciones en los varones, cuya cxplicación supera las posibilidades de este análisis.

Los niffos de esta serie se caracterizaban por contar con varios factores favorables para su salud, como buenos peso de nacimiento, desarrollo y estado de nutrición; madres de cdad adecuada para la crianza; de educación aceptable para nuestro país (si bien menor que en otros de mayor desarrollo) $)^{7,8.11}$, pocas de las cuales trabajaban fuera del hogar, pudiendo la mayoría de ellas cuidar a sus niños personalmente y cumplir bien los controles de salud prescritos. Por esta razón, la alta frecuencia de trastornos respiratorios bajos, registrada a pesar de las ventajas aludidas, hace suponer otros factores de mayor peso, posi- blemente relacionados con situaciones economicas desfavorables, que determinen viviendas poco apropiadas, contaminación intradomiciliaria con combustibles inadecuados para calcfacción, humo de cigarrillo y hacinamiento, cuya contribución ha sido comprobađa en otros países ${ }^{5-7}$. Además Santiago es una de las ciudades cuya atmósfera está más contaminada en cl mundo ${ }^{12.13}$, de lo que surge la conveniencia de comparar las cifras encontradas en este estudio con las de niños que habitan regiones no contaminadas.

\section{Resumen}

Se rcalizó un scguimiento de dieciocho mescs, prospectivo, a una cohorte de 423 niưos sanos nacidos cntre mayo 1991 y abril 1992, de peso normal al nacer, en un consultorio urbano de la Región Metropolitana. Se registraron 877 episodios de afecciones respiratorias bajas (bronquitis, sindrome bronquial obstructivo y neumopatías) entre 235 niños, de 305 que habían cumplido 18 mescs de observación. La incidencia global de enfermedades respiratorias bajas agudas fue de 17 por cada 100 niños por mes de observación en cada uno de los tres semestres del estudio. La proporción en que estos trastomos ocurrieron fue $46,6 \%$ bronquitis, $40,1 \%$ síndrome bronquial obstructivo y $13,2 \%$ neumonías. El promedio de cpisodios por niño en cada semcstre fuc de 2,15 , 1,96 y 1,90 , respectivamente, para el total de afecciones. La proporción de niños con problemas respiralorios bajos disminuyó con el aumento de la cdad, no así el promedio de episodios por niño. La frecuencia de cstas afecciones fue mayor en varones: en hijos de madres con menos de 8 años de asistencia a la escuela; en niños cuyas madres u otros miembros de la familia fumaban, y entre aquellos en cuyo hogir se usaban combustibles contaminantes para calefacción. Los nifnos que nacen entre diciembre y febrero presentaron tasa más altas de bronquitis y síndrome bronquial obstructivo en el primer semesure de vida.

(Palabras clave: lactantes, infecciones respiratorias agudas bajas.)

\section{Referencias}

1. Orsanización Panamericana de la Salud: Organización Munctial de la Salud. Informe Programa I.R.A. de la O.M.S. 1990; 1-2. 
2. Lopez I, Sepúlveda II: Egresos de menores de 15 años еп area Consultorio J. Symon Ojeda. Hosp. R. del Río 1988 a 1990 . Pediatria/1991: 34: 88-92.

3. Kaempffer AM, Medina E: Hospitalización Infantil en Chile, situación actual y perspectivas. Rev Chil Pediatr 1992; $110-117$.

4. Ministerio de Solud. Sectetaria Regional Ministerial. Asesoría de Estadística. Indicadores de Atención de Salud. Región Metropolitana. Anuario 1992: 7; 25-27.

5. Chenker MB, Samet JM, Speizer FE: Risk Factors for chilhood respiratory diseases. The effects of home factors and home environmental exposures. Am Rev Respir Dis 1983; 128 : 1083-1043.

6. Lebowitz $M D$ : The relationship of social environmental factors to the prevalence of obstructive lung diseases and other chronic conditions. J Chronic Dis 1977; 121: 3-10.

7. Tager IB, Weiss ST, Munoz A, Rosner B, Speizer FE. Longiudinal study of the effects of matemal smoking on pulmonary function in children. $\mathrm{N}$ Engl J Med 1983; 309: 699.703.

8. Woodward A, Douglas RM, Graham NMH, Miles $H$ : Acute respiratory illness in Adelaide children. Breası feeding modifies the effect of passive smoking. J Epidemiology and Comonity Health 1990; 44: 224-230.
9. Valenzuela J. Dlaz E, Klaggs B: Empleo de un nuevo mćtodo de clasificación social. Cuademos Médicos Sociales 1976; 17: 14-22.

10. Taussig LM, Wright AL, Morgon WJ, Marrison $H R$, Ray CG and the Group Heaith Medical Associates. The Tusson Children's Respiratory Study. I Design and Implementation of a prospective study of acute and Chronic Respiratory Illness in children. Am J Epidemiol 1989; 129: 1219-1231.

11. Wright AL, Taussig LM, Ray CG, Harrison HR, Holberg CJ: The Tucson Children's tespiratory study. II Lowter Respiratory Ilness in the first year of life 1987 Am J Epidemiol 1987: 1232-1246.

12. Aranda $C$. Belmat $R$, Bello $S$, Mwîoz M. Skeppard D, Oyarzún $M$ : El problema de la contaminación atmosférica en la ciudad de Santiago. Enf Respir Cir Torac 1990: $6 ; 69-78$

13. Love GJ, Lan S, Shy CM, Struba RJ: The incidence and severity of accute respiratory illness in families exposed to different levels of air pollusion. New York Metropolitan Area 1971-72. Arch Environ Health 1981: 36; 66-73.

14. Phelan PD, Landak $L$, Olinsky A: Respiratory illness in children. $2^{\text {nd }}$ ed. A Oxford: Blackwell Scientific Publications, 1982: 32-38. 